\title{
Exploration of Niche Market and Innovation in Organic Textile by a Developing Country
}

\author{
Muhammad Abrar \\ School of Management \\ Huazhong University of Science and Technology \\ Wuhan 430074, China
}

Tel: 86-27-6386-2592Ｅ-mail: abrarhust@gmail.com

Zhilong Tian (Corresponding author)

School of Management

Huazhong University of Science and Technology

Wuhan 430074, China

Tel: 86-27-8755-6482 E-mail: zltian@mail.hust.edu.cn

\author{
Xinming Deng \\ School of Economics and Management \\ Wuhan University \\ Wuhan 430072, China \\ E-mail: xm_deng@163.com
}

\begin{abstract}
In today's challenging economic environment, innovation is a process of generating new ideas that will prevent a company from stagnation by giving its products and services a competitive edge, a compass by which the business entities would set their directions and would adopt it as a core business strategy for going forward. And customers are now more knowledgeable than ever, about the impacts of business on society and environment, so this is the time for transition to organic methods and eco-friendly products. Objectives of this study are to foresee the opportunities available in the organic textile niche markets, and examine how niche marketing and innovation is helpful to exploit these opportunities in the developing world, exclusively Pakistan, where economy mainly relies on agro-based industries with textile as a major player. Pakistan is one of the largest cotton producers in the world and due to cheap labor, has a relative advantage in producing and exporting organic textile products, as compared with developed countries. By exploiting niche market opportunities with introducing a variety of organic textile products in an innovative way, can bring a substantial amount of earnings for Pakistan.
\end{abstract}

Keywords: Innovation, Niche marketing, Organic textile, Product innovation, Developing countries

\section{Introduction}

In present competitive global business environment, innovation is like a compass by which the business entities would set their directions and would adopt it as a core business strategy for going forward. From marketing point of view innovation is a tool to face the competition from competitors. The concept of innovation is another milestone in modern international marketing strategy because in today's dynamic and competitive market environment many senior managers have become increasingly concerned with the need to be first, fast, and on time (Wong, 2002). In this competitive environment the firms can only compete either by reducing the cost or by innovation. By reducing the cost of production and keeping their products different from their competitors, firms can enjoy the benefits of competitive 
marketing environment (Porter, 1980).The innovation has four key dimensions that serve as business anchors; strategy innovation; product innovation; process innovation and market innovation (Henard \& Szymanski, 2001), each dimension requiring a different set of capabilities that can't be developed or acquired overnight. Innovating along one dimension often influences choices with respect to other dimensions. As such, selecting and acting on dimensions that define a firm's innovation strategy requires a deliberate, portfolio-based approach that must be communicated clearly within the company as well as to external constituents (Mohanbir et al., 2006).

Pakistan is agriculture based country and fourth largest producer of cotton. Textile industry in Pakistan is facing strong competition in cost from other textile players. Innovation is one of the obvious options to cope with this brutal competition. As Lukas and Ferrell point out, both marketing and innovation are vital stimuli for economic growth and contribute in competitive advantage (Lukas \& Ferrell, 2000). Business innovation is a creation of substantial new value for customers and the firm by creatively changing one or more dimensions of the business system. Worth of an innovation is decided by the customers, when they vote with their wallets. It makes no difference how innovative a company thinks it is; what matters is whether customers will pay. Today most firms and organizations need a continual flow of dynamic new strategies, to harness their resources and energy to the cause of continuous innovation (Pierre L. et al., 2001).

Consumers doubt not only the quality but also the very greenness of green products, therefore to build public trust, organic textiles must meet certain requirements for certification, at all stages through the processing chain, only then will consumers believe an organization's green claims. Besides the assurance that organic and conventional fibers are not commingled and that organic fibers are not contaminated; the dyestuffs and other chemicals used- especially in relation to toxicity and biodegradability, waste water treatment, wet and dry processing methods used even in finishing process and social issues like worker conditions should also be maintained according to certain standards. Pakistan is an agriculture country and has comparative advantage to grow organic cotton more efficiently in some parts of Balochistan and Sindh provinces; where people still rely on biological farming methods. Organic textile is currently a niche market as compared to traditional textile and in a niche market usually, the profits are high due to less competition. Niche marketing has been used synonymously with market segmentation, target marketing, micromarketing, regional marketing, focused marketing and concentrated marketing (Dalgic \& Leeuw, 1994, Kara \& Kaynak, 1997). In niche marketing strategy, all the organizational efforts are used to satisfy the targeted customers, at substantial profits. And niche marketing strategy, being more focused and targeted to customers, can be utilized to market the organic textile products. By growing organic cotton, Pakistani farmers can exploit the opportunities offered by this niche market. To achieve this goal; in addition to hard work and biological farming methods, which they already are following, they need awareness, marketing and proper guidance. Retail sales of organic cotton products are estimated to grow up to $\$ 3.5$ billion in 2008 and $\$ 6.8$ billion by the end of 2010 (Organic exchange, 2007). In this paper we tried to explain that how innovation and niche marketing, if embedded in organic textile can help Pakistan to explore the potential opportunities.

\section{Innovation}

The core renewal process in any organization, which creates value for customers, is called innovation. Unless an organization changes what it offers the world, and the ways in which it creates and delivers those offerings; it risks its survival and growth prospects. Merely creating "new things" is neither necessary nor sufficient for business innovation and this is not an automatic attribute of an organization; the process has to be enabled through sophisticated and active management. There are no guaranteed formulae for success in what is inevitably a risk-based activity, but extensive research dating back over a century suggests a series of convergent themes from which guidelines for effective innovation management can be extracted (Tidd et al., 2001). A company can't outgrow its competitors unless it can out-innovate them. Innovation is a poorly explored area with respect to organic textile. Organic textile niche market has potential opportunities; if exploited in combination with innovation can bring substantial amounts of earnings for the Pakistani textile industry. Now we discuss the strategy innovation, product innovation, process innovation and market innovation one by one.

\subsection{Strategy innovation}

Strategy innovation is improving, changing, and challenging the existing industry methods to create new markets, to add additional value, and meet newly emerging customer needs. Strategy innovation approaches are of two types: radical strategy innovations and incremental innovations (Hax, 1989). Most of the textile organizations are using the mass marketing strategy. But if a firm wants to gain the competitive advantages of micro marketing strategy or niche marketing strategy, this is also a strategy innovation. Firms seek to improve fit between their offerings and customer needs by surveying customers and importing knowledge from leading-edge customers into the firm (von Hippel, 1988). A niche market strategy emphasizes on a particular need, or, geographic, demographic or product segment (Teplensky, Kimberly, Hillman \& Schwartz, 1993). The textile organization can use either incremental strategy approach i.e. first choose eco-textile then convert it into organic textile or radical strategy innovation approach which directly goes towards organic textile. 


\subsection{Product innovation}

Product innovation is the result of bringing to life a new way to solve the customer's problem - through a new product development and is the most important source of revenue generation for the company (Johne, 1999). Sometimes product innovation becomes mandatory in textile organizations like eco-textiles. In European market there are strict laws and regulations about certain dyes and chemicals which are used in the dyeing, printing and finishing process of the textile value chain. Some of the chemicals used in this value chain are carcinogenic and some are not environment friendly. So the innovations brought about by certain laws, technical requirements and on customer demand are called mandatory or obligatory innovations. The other type of innovation is voluntary product innovation like organic textile products. Because the firm decides to produce these textile products keeping in view the opportunities, higher margins of profit, growth potential available to sell these products in the market.

\subsection{Process innovation}

Process innovation emphasizes on, integrating new production methods and technologies that lead to improved efficiency, quality, or time-to-market, and services that are sold with those products and can be achieved through small improvements in the process, sub-processes or redesigning the processes. The process innovations include, among other aspects, issues relating to new skills and abilities, a greater concern for market orientation and the development of inter-departmental communication (Henard \& Szymanski, 2001). Suppose a traditional textile organization decides to exploit the niche market opportunity; may be called as strategy innovation, and choose the organic textile products to exploit this opportunity; would be referred to as product innovation. For producing the organic textile products in the textile value chain there are many processes which should be improved or changed to meet the global organic textile standards which come under the category of process innovation. The process innovation can also be used to improve the quality of products by improving or eliminating certain processes. Process innovation hugs quality function deployment and business process reengineering (Cumming, 1998).

\subsection{Market innovation}

In a market economy, in addition to innovations in products and production processes, there are also innovations in the marketing of products. The development of new marketing tools and methods plays an important role in the evolution of industries (Yongmin Chen, 2006). First identify the potential markets, through adroit market segmentation. Market segmentation is chiefly based on the imaginative recognition of budding market opportunities (Johne, 1999). The organizations can also identify market potential through market research. The market innovations can be differentiated into pull market innovations and push market innovations (Tornatzky \& Fleischer, 1990). The market pull model suggests that the stimulus for innovation comes from the needs of society or a particular section of the market whereas in push market model, the "innovation push" itself projects organization for new innovations (Kaplan, 1999). Nike and Wal-Mart have been selling the organic textile products for last couple of years and their products primarily create their own demands, especially Nike. In case of pull market innovation approach the firms identify the demand of a certain product and then respond accordingly. As some of Pakistani textile organizations are exploiting the organic textile niche market opportunities available in the European and American markets which is an example of pull market innovation approach. The identification of new market opportunities, and then reaping these opportunities efficiently and effectively, is a challenging task. The organizations and persons meeting this task are called market champions as Nike, Wal-Mart, C \& A; they are the market champions in organic textile products. Market champions see new market opportunities and point out how the needs of chosen markets might best be served, and these companies are capable of making and reshaping the markets (Johne, 1996).

\section{Niche Marketing}

Today, green products and services, exclusively the organic textile, are only a niche market, but they are poised for strong growth. Niche marketing is the splitting of conventional markets into smaller segments and then devising separate marketing programs for each of these smaller segments or niches (Linneman \& Stanton, 1992). Establishing a niche market provides an opportunity to an organization to sell products and services to a group that has been overlooked by other businesses. Textile industry already has a well established market. If divided in to smaller segments like medical textile, nano textile, organic textile, and industrial textile then all these segments would be called as niche markets. There is a slight difference between market segmentation and niche marketing. Market segmentation is the process in which large markets are broken down in to smaller and more manageable market segments which is called top down approach. On the other hand a niche market starts from the needs of a few customers and then gradually builds up in to large markets or customer base, called as bottom up approach (Shani \& Chalasani, 1992). Niche marketing is one-step ahead of market segmentation because it creates a discrete group of customers (Kara \& Kaynak, 1997). In niche marketing the customer has separate needs, and then the whole company's efforts are to satisfy those needs at higher profit margins as compared to mass market. Niche marketers often progress to mass marketers and mass marketers go back to niche marketers. Most of the organizations start out as niche marketers and evolve in to mass marketers, when the saturation starts and product reaches at maturity, innovation occurs and former mass markets are 
inclined to come back to niche markets (Dalgic \& Leeuw, 1994). Most of the traditional textile items are at maturity stage and there is a tough competition in the mass market to sell out these products even at nominal profits, so there is an opportunity for Pakistani textile organization to earn higher profit margins from niche market like "organic textile". The characteristics of niche market can be defined as; the customers in niche have a distinct set of needs, greater profit margins due to premium price, can gain certain economies through specialization, niche has size, profit and growth potential, not likely to attract competitors (Kotler, 2003). Keeping in view above niche market characteristics, if we analyze the organic textile, we see that organic consumers need environment friendly products free of chemicals and hazardous materials. The organic textile products are sold at almost double price than the traditional ones. This market has been growing at a rate of more than fifty percent annually for the last couple of years.

\section{Organic Textile}

Green campaigns are being launched by organizations of all types, and the impulse to go "green" is spreading faster than morning glories. Organic textile is a kind of textile which is based on at least ninety five percent of organic cotton or other organic fibers and the processing of organic textile should meat any one of the several standards certified by a qualified certifying organization (Sall, 2003). Organic textiles are also called environment friendly textiles or green textiles. Organic cotton fiber is used in everything from personal care items (sanitary products, make-up removal pads, cotton puffs and ear swabs), to home furnishings (towels, bathrobes, sheets, blankets, bedding), children's products (toys, diapers), and clothes. In addition, organic cottonseed oil is used in a variety of food products. Most astonishing, perhaps, is increasing resolve to organic fiber from big players including Wal-Mart, Nike, Marks \& Spencer, and C \& A which are showing a yearning to be good corporate citizens by reducing the ecological impact of their relevant apparel supply chains. The textile sector is a very complex and diverse sector; a lot of processes are involved during the textile value chain to form a finished product which finally reaches the consumers (Abrar, Zhilong, Usman, Ali, 2008). In the organic textile business everyone wants to know each other from raw material producers like farmers to end retailers like Nike and Wal-Mart. Strong commitments as well as regulations are required to fulfill the global organic textile standards at every step of textile value chain to deliver the certified organic textile products to end consumers. Given, these unique requirements and regulations, there is a higher cost in textile value chain process to produce and deliver the organic textile products. That's why most of the organic textile suppliers have developed a completely vertical integration from organic cotton to finished textile products. In this way these organizations ensure the compliance issues and supply by managing and keeping the cost low to make the organic textile profitable and affordable to end consumers. Conventionally grown cotton is the second most pesticide laden crop after coffee. It is estimated that it takes around one-third pound of chemicals to grow sufficient cotton to make just one T-shirt (Ryciak, 2006). In place of chemicals the farmers mainly use organic fertilizers, crop rotation and integrated pest management to grow organic cotton. Commercial organic cotton production is now on the move in some twenty two countries across America, Asia, Mediterranean, and Africa (EJF, 2007).

\section{Opportunities for developing countries}

Organic farming has been chiefly beneficial in developing countries, exclusively Pakistan, for a host of reasons. Organic farming encourages the use of labor, which is in surplus and cheap in Pakistan. The conversion from traditional farming to organic farming in developing countries is comparatively easier than developed countries. Because the farmers in developing countries like Pakistan are using less fertilizers, pesticides, herbicides and genetically modified seed due to their high prices and low availability as compared to the farmers of developed countries like America and Australia. Turkey is a developing country where organic food farming is ascending and the farmers are also encouraged to grow organic cotton by utilizing the crop rotation techniques as well. Turkey also ranks first in the production of organic cotton (Organic Trade Association, 2008). Pakistan is world's fourth largest producer and the third largest consumer of cotton. Cotton based textile constitutes over 60 percent of the total exports, it accounts for 46 percent of the total manufacturing and provides employment to about 38 percent manufacturing labor force (Economic survey of Pakistan, 2006-2007). Pakistan merchandise exports rely on the textile products predominantly and due to severe global competition in this mature sector there is a very slow growth and little profit margins in the exports of traditional textile items. So another option for textile exporters in Pakistan is to exploit the niche market opportunities available in this mature sector. These niche markets are medical textile, industrial textile, technical textile and organic textile. Being an agricultural and developing country, Pakistan has a comparative advantage in exploiting the organic textile niche market opportunities. In this way not only they can earn more profit but can also contribute in economic growth and well being of their country. Because organic textile is chiefly based on organic cotton and subsequent green value addition processes in the textile value chain, it is labor intensive which is cheap and abundant in Pakistan. The organic cotton is a niche market to be exploited by developing countries. Due to less dependence on chemicals and fertilizers for the production of organic cotton, developing countries need only little adjustments in their current production practices (Baffes, 2004). In this way they can easily qualify as certified organic cotton producers. To label and market a textile product as organic, certification of the cotton fiber along with its subsequent value addition processes is a pre-requisite. 


\section{Conclusion}

In today's challenging and ever-changing business environment, any economy needs innovation to thrive. This can only be achieved through specialization; product differentiation and exploiting the new market opportunities, like niche markets having size, profit, and growth potential. And customers are now more knowledgeable and aware than ever before, about the impacts of business on society and environment, so this is the time for transition to organic methods and eco-friendly products. Organic farming, exclusively the organic cotton is a new opportunity to increase the farm earnings in the developing countries. In this study we choose the textile sector due to strong competition around the globe and its importance in the economy across the developing world. Pakistan is primarily an agro based country and its exports are chiefly loaded with textile products, has a comparative advantage to produce the organic cotton due to cheap labor and its profusion in the country and rest of value chain processes are also labor dependent. Organic textile is a niche market having size, higher profit margins and growth potential along with the improvement of ecosystem and social well being. The other niche market opportunities are nano textile, medical textile, and industrial textile which are capital intensive. Organic textile is a new idea and product with substantial opportunities, and should be explored empirically with innovation and niche market point of view. More extensive studies are required to further elaborate its significance.

\section{Acknowledgement}

The authors are deeply grateful to thoughtful participants of "The 5th International Conference on Innovation and Management (ICIM2008) Maastricht, the Netherlands", for their invaluable comments and suggestions, which considerably enhanced and improved the preliminary version of this article.

\section{References}

Abrar, M., Zhilong, T., Usman, M., \& Ali, A. (2008). E-Marketing morphology in the textile sector of Pakistan. Proceedings of the Seventh Wuhan International Conference on E-business: Vol.1, pp. 1-8. New York: Alfred University Press.

Baffes, J. (2004). Cotton: market setting, trade policies, and issues. [Online] Available: http://www-wds.worldbank.org/servlet/WDSContentServer/WDSP/IB/2004/06/03/000009486_20040603091724/Rende $\mathrm{red} / \mathrm{PDF} / \mathrm{wps} 3218$ cotton.pdf (July 20)

Chen, Y. (2006). Marketing Innovation. Journal of Economics \& Management Strategy, 15, 101-123.

Cumming, B.S. (1998). Innovation overview and future challenges. European journal of innovation management, 1 (1), 21-29.

Dalgic, T., \& Leeuw, M. (1994). Niche marketing revisited: concept, applications, and some European cases. European Journal of Marketing, 28 (4), 39-55.

Economic survey of Pakistan. (2006-2007). Manufacturing and mining. [Online] Available: http://www.finance.gov.pk/admin/images/survey/chapters/03-Manufacturing.PDF (July 25)

EJF. (2007). The Deadly Chemicals in Cotton, Environmental Justice Foundation in collaboration with Pesticide Action Network UK, London. Retrieved July 24, 2008.

Glen, L., Urban \& Hippel, V. E. (1988).Lead user analyses for the development of new industrial products. Management Science, 34 (5), 569-582.

Hax, A.C. (1989). Building the firm of the future. Sloan Management Review, 30 (3), 75-82.

Henard, D., \& Szymanski, D. (2001). Why some new products are more successful than others. Journal of Marketing Research, 38 (3), 362-375.

Johne, A. (1996). Succeeding at product development involves more than avoiding failure. European Management Journal, 14 (2), 176-180.

Johne, A. (1999). Successful Market Innovation. European Journal of Innovation Management. 2 (1), 6-11.

Johne, A. (1999). Using market vision to steer innovation. Technovation, 19, 203-207.

Kaplan, S. M. (1999). Discontinuous innovation and the growth paradox. Strategy \& leadership, 27 (2), 16-21.

Kara, A., \& Kaynak, E. (1997). Markets of a single customer: exploiting conceptual developments in market segmentation. European journal of marketing, 31 (11/12), 873-896.

Kotler, P. (2003). Marketing management. (11th ed.). Upper Saddle River, NJ: Prentice-Hall.

Linneman, R.E., \& Stanton, J. L. (1992). Mining for niches. Business Horizons, 35 (3), 43-52.

Loewe, P., Williamson, P., \& Wood, C. R. (2001). Five styles of strategy innovation and how to use them. European Management Journal, 19 (2), 115-125. 
Lukas, B. A., \& Ferrell, O, C. (2000). The effect of market orientation on product innovation. Journal of the academy of marketing science, 28 (2), 239-247.

[Online] Available: http://seattle.consciouschoice.com/2006/09/f3_clothes_call.html

[Online] Available: http://www.ejfoundation.org/pdf/the_deadly_chemicals_in_cotton.pdf

[Online] Available: http://www.organicexchange.org/Documents/market_high_fall07.pdf

[Online] Available: http://www.ota.com/organic/environment/cotton_environment.html

Organic exchange. (2007). Organic cotton market report. From Organic Trade Association. Cotton and the environment. (July 25, 2008).

Porter, M. (1980). Competitive strategy: Techniques for analyzing industries and competitors. New York: Free Press.

Ryciak, R. (2006). Clothes call: More consumers are connecting organic to their wardrobes. We make a case for organic cotton. (July 22, 2008).

Sall, K.S. (2003). Feasibility study on marketing of organic cotton products and certification of organic cotton and textile $\quad$ production. $\quad$ Anline] $\quad \mathrm{http}: / / \mathrm{www}$. ncpc.co.za/ncpc_ct/documents/Organic\%20cotton\%20feasibility\%20study.pdf(July 03)

Sawhney, M., Wolcott, C. R., \& Arroniz, I. (2006). The 12 different ways for companies to innovate. MIT Sloan Management Review, 47 (3), 75-81.

Shani, D., \& Chalasani, S. (1992). Exploiting niches using relationship marketing. The Journal of Services Marketing, 6 (4), 43-52.

Teplensky, J.D., Kimberly, J.R., Hillman, A.L., \& Schwartz, J.S. (1993). Scope, timing and strategic adjustment in emerging markets: manufacturer's strategies and the case of MRI. Strategic Management Journal, 14 (7), 505-527.

Tidd, J., Bessant, J., \& Pavitt, K. (2001). Managing Innovation: Integrating technological, market and organizaional change. ( $3^{\text {rd }}$ ed.). John Wiley and Sons,UK.

Tornatzky, L. \& Fleischer, M. (1990). The process of technological innovation. New York: Lexington Books.

Wong, V. (2002). Antecedents of international new product rollout timeliness. International Marketing Review, 19 (2), $120-132$. 


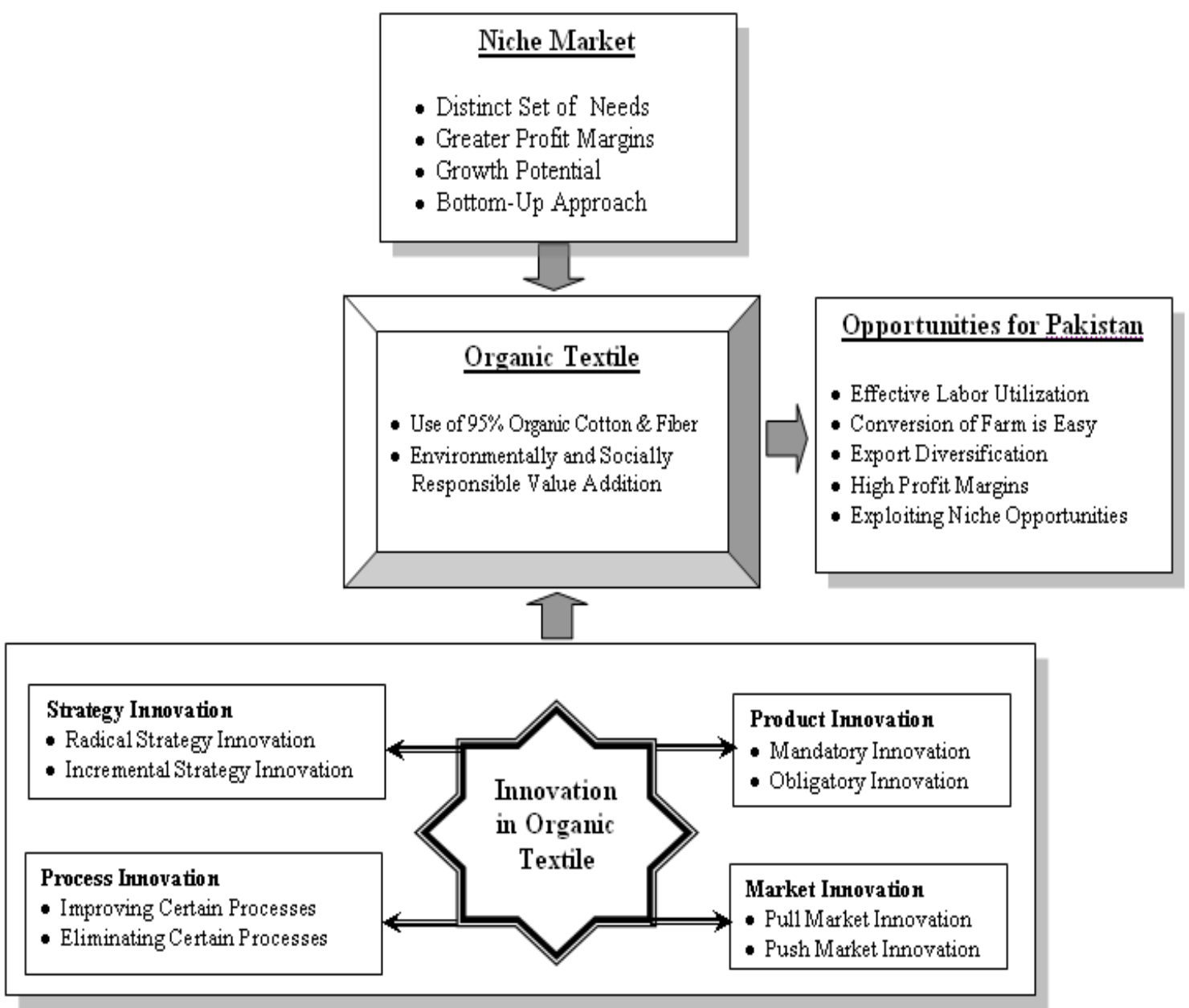

Figure 1. Innovation and Niche Marketing in Organic Textile 